\title{
Extratos de Achyrocline satureioides (Lam.) DC. sobre a germinação “in vitro" de Eragrostis plana Nees ${ }^{1}$
}

\author{
Jéssica Mena Barreto de Freitas², Kássia Cauana Trapp ${ }^{3}$, Andrielle Wouters Kuhn ${ }^{4}$, Aline \\ Augusti Boligon ${ }^{5}$, Viviane Dal-Souto Frescura ${ }^{6}$, Naylor Bastiani Perez ${ }^{7}$, Solange Bosio \\ Tedesco $^{8}$
}

\begin{abstract}
Resumo: A gramínea exótica Eragrotis plana Nees, conhecida como capim-annoni, é uma das principais plantas invasoras do Sul do Brasil, com a capacidade de excluir outras plantas nativas da vegetação campestre. Há uma necessidade tanto ambiental como econômica do seu controle. $\mathrm{O}$ objetivo foi avaliar o efeito dos extratos aquosos da espécie Achyrocline satureioides (Lam.) DC. sobre a germinação in vitro de Eragrostis plana Nees, bem como identificar os compostos presentes nesses extratos aquosos. Para preparação dos extratos foi realizada infusão de flores de A. satureioides em quatro concentrações $5,10,15,25 \mathrm{~g} \mathrm{~L}^{-1}$, as quais foram avaliadas juntamente com um controle (água destilada). Todas as concentrações de extratos foram analisadas por Cromatografia Líquida de Alta Eficiência (CLAE-DAD). A seguir, foi realizado o teste de germinação e vigor das sementes de E. plana. Em relação à porcentagem de germinação de sementes de capim-annoni, os valores obtidos demonstraram redução da porcentagem na maior concentração do extrato de marcela. Quanto ao Índice de Velocidade de Germinação, todas as concentrações de extratos de marcela reduziram a velocidade de germinação. Para a análise dos compostos presentes nos extratos estudados, a CLAE-DAD revelou maiores teores de rutina, ácido caféico e quercitrina. Os extratos de A. satureioides reduzem a porcentagem de germinação.
\end{abstract}

Palavras-chave: ácidos fenólicos; capim-annoni; flavonoides; gramínea exótica, planta invasora.

\section{Extracts of Achyrocline satureioides (Lam.) DC. on germination "in vitro" Eragrostis plana Nees}

\begin{abstract}
The exotic grass Eragrotis plana Nees, known as tough anonni-grass, is one of the main invasive plants of southern Brazil, with the ability to exclude other natives rangeland plants. There is an environmental as well as economic necessity of its control. The objective was to evaluate the effect of the species Achyrocline satureioides (Lam.) DC. on the in vitro germation of Eragrostis plana Nees, as well to identify the compounds present in these aqueous extracts. For the preparation of the extracts was performed by infusion of the flowers of the A. satureioides in four concentrations of $5,10,15,25 \mathrm{~g} \mathrm{~L}^{-1}$, which were evaluated along with a control (distilled water). All extracts concentrations were analyzed by High Performance Liquid Chromatography (HPLC-DAD). Next, the seed germination and vigor test of the E. plana was carried out. As for the germination percentage of the seeds annoni-grass, the values obtained showed a reduction in the percentage in the highest concentration of the marcela extract. Regarding Germination Rate Index, all concentrations of marcela extracts reduced the germination speed. For the analysis of the compounds present in the extracts studied, the HPLC-DAD revealed higher levels of rutin, caffeic acid and quercitrin. The extracts of $A$. satureioides reduction the germination percentage.
\end{abstract}

Keywords: phenolic acids; annoni-grass; flavonoids; exotic grass; invasive plant.

\footnotetext{
${ }^{1}$ Submetido em 29/06/2018 e a provado em 17/11/2018

${ }^{2}$ Biológa; Estudante de Mestrado, Universidade Federal de Santa Maria (UFSM), Centro de Ciências Naturais e Exatas, Programa de PósGraduação em Agrobiologia, Santa Maria-RS, CEP: 97105-900; E-mail: jessicamenabarretofreitas@ gmail.com

${ }^{3}$ Mestre em Agrobiologia; Bolsista CNPq, Estudante de Doutorado, Universidade Federal do Rio Grande do Sul (UFRGS), Faculdade de Agronomia, Programa de Pós-Graduação em Fitotecnia, Porto Alegre-RS, CEP: 91540-000; E-mail: kassiacauanatrapp@ yahoo.com.br ${ }^{4}$ Doutora em Agronomia; Universidade Federal de Santa Maria (UFSM), Santa Maria-RS, CEP: 97105-900; E-mail: andrikuhn@hotmail.com

${ }_{5}^{5}$ Doutora em Ciências Farmacêticas; Universidade Federal de Santa Maria (UFSM), Santa Maria-RS, CEP: 97105-900; E-mail: alineboligon@gmail.com

${ }^{6}$ Doutora em Agronomia; Professora, Universidade Federal de Santa Maria (UFSM), Coordenadoria Acadêmica, Cachoeira do Sul-RS, CEP: 96506-322; E-mail: viviane.frescura@ufsm.br

${ }^{7}$ Doutor em Zootecnia; Pesquisador, Embrapa Brasileira de Pesquisa Agropecuária (EMBRAPA CPPSul), Departamento de Pesquisa e Difusão de Tecnologia, Bagé-RS, CEP: 96401-970; E-mail: naylor.perez@embrapa.br

${ }^{8}$ Doutora em Zootecnia; Professora, Universidade Federal de Santa Maria (UFSM), Centro de Ciências Naturais e Exatas, Programa de PósGraduação em Agrobiologia, Santa Maria-RS, CEP: 97105-900; E-mail: solatedesco@ gmail.com
} 


\section{Introdução}

A espécie forrageira Eragrostis plana Nees, Poaceae, conhecida popularmente por capimannoni, é uma planta perene, estival e de fácil dispersão (Ferreira et al., 2008). Foi introduzida no Brasil na década de 50, principalmente no Rio Grande do Sul, sendo considerada posteriormente uma planta invasora. Vinda da África do Sul, sua introdução involuntária no Estado passou a representar um problema a partir dos anos de 1970 (Reis e Oliveira, 1978). Além do baixo valor nutritivo, sendo normalmente rejeita pelos animais no campo (Lisboa et al., 2009), possui potencial alelopático, com grande poder de exclusão de outras plantas residentes da comunidade vegetal nativa (Ferreira et al., 2008; Fiorenza et al., 2016). Com a expansão de E. plana em determinadas áreas fica difícil seu extermínio, sendo utilizados herbicidas e queimadas, causando prejuízos ambientais.

Seu impacto negativo vem causando perda de riqueza de espécies, assim como o empobrecimento da qualidade forrageira dos campos (Focht, 2008). Sem uma grande alteração nas práticas de controle e redução da taxa de expansão desta invasora, os campos naturais do Rio Grande do Sul continuarão em progressiva degradação. As dificuldades para o controle de sustentabilidade da propriedade rural aumentarão, diminuindo a rentabilidade pecuarista no Estado (Pillar et al., 2009).

Há plantas medicinais que através da sua ação antiproliferativa acabam diminuindo, ou até mesmo, inibindo a germinação de outras plantas, como ocorreu com Cyperus rotundus L. tratadas com extratos de mucuna-preta (Mucuna pruriens (L.) DC var. utilis (Wight) Burck), onde houve a diminuição do crescimento da parte aérea de $C$. rotundus (Almeida e Câmara, 2012). Quando sementes de alface foram tratadas com extratos de raízes e folhas de Croton glandulosus ocorreu redução da sua germinação, demonstrando o efeito antiproliferativo dos extratos dessa planta (Kremer et al., 2016). Em trabalho utilizando extratos de Melaleuca alternifolia Cheel, também foi verificada a redução da porcentagem de sementes germinadas da espécie Brachiaria brizantha (Hochst. ex A. Rich.) Stapf (Queiroz et al., 2016).
Quanto aos extratos da espécie Achyrocline satureioides (Lam.) DC., Fachinetto et al. (2007) demonstraram, por meio do teste de Allium cepa L., que as infusões inibiram a divisão celular de células meristemáticas. Comprovado, também, por Oliveira et al. (2014), os extratos de sementes dessa espécie reduzem em até $50 \%$ a germinação de sementes de Lactuca sativa L., em altas concentrações. Tais estudos evidenciam o efeito antiproliferativo da espécie. Além disso, extratos alcoólicos e decoctos de inflorescências de A. satureioides apresentam ação antibacteriana, com capacidade de inativação e inibição in vitro de inóculos bacterianos (Mota et al., 2011).

A espécie tem em sua composição o ácido caféico, a quercetina, a luteolina e a 3-Ometilquercetina como principais componentes, os quais foram detectados em produtos secos da planta, por meio da técnica de Cromatografia Líquida de Alta Eficiência (CLAE) (Holzschuh, 2008). A CLAE apresenta-se como uma técnica eficiente para separação e isolamento de substâncias a partir de extratos vegetais. Esse método analítico é utilizado, principalmente, para fins qualitativos e quantitativos. Sua alta utilização é justificada pela sua boa sensibilidade em determinações quantitativas, além de separar espécies não voláteis e termicamente instáveis, sendo importante no ramo farmacêutico (Tonhi et al., 2002).

A CLAE é uma técnica permite a avaliação de diferentes compostos (Souza-Moreira et al., 2010) como, compostos fenólicos, terpenos e alcaloides. Por meio disso, esse método é útil em pesquisas que avaliam a ação desses componentes, presentes em extratos vegetais, sobre a germinação de sementes de outras espécies (Pereira et al., 2018).

Levando em consideração o que se sabe a respeito de A. satureioides, o objetivo foi avaliar o efeito dos extratos aquosos da espécie Achyroclines satureioides (Lam.) DC. sobre a germinação in vitro de Eragrostis plana Nees, bem como identificar os compostos presentes nesses extratos aquosos.

\section{Material e Métodos}

O trabalho foi realizado no Laboratório de Citogenética Vegetal e Genotoxicidade (LABCITOGEN), do Departamento de Biologia, 
na Universidade Federal de Santa Maria (UFSM), Santa Maria, RS. As sementes de E. plana foram obtidas de plantas mantidas em estufa plástica, durante os anos de 2012 e 2013. Essas plantas vieram do município de Bagé, RS, onde estavam depositadas na coleção da Embrapa Pecuária Sul (CPPSul). Enquanto que as flores, de dois indivíduos, de A. satureioides utilizadas no preparo de extratos aquosos foram coletadas no Cerrito do Ouro, município de São Sepé, RS (30²'50.7"S 53³9'57.5"W e altitude de $2928 \mathrm{~m})$.

\subsection{Extratos de Achyrocline satureioides sobre a germinação das sementes de Eragrostis plana}

O preparo dos extratos foi realizado por infusão das flores de A. satureioides em água destilada nas concentrações 5, 10, 15 e $25 \mathrm{~g} \mathrm{~L}^{-1}$. As flores foram colocadas em contato com água destilada fervente, onde permaneceram por 10 minutos e então foram coadas. Todas as concentrações de extratos foram analisadas por Cromatografia Líquida de Alta Eficiência (CLAE-DAD).

Para a germinação das sementes foram utilizadas placas de Petri recobertas com duas folhas de papel filtro cada. Acima dessas folhas foram colocadas para germinar sementes de $E$. plana, as quais permaneceram em câmara de crescimento à $25^{\circ} \mathrm{C}$ e com fotoperíodo de $12 \mathrm{~h}$. Foram colocadas 50 sementes em cada placa, sendo utilizadas quatro repetições, totalizando 200 sementes por tratamento, os quais estão descritos a seguir:

T1-água destilada (controle), T2 - extrato aquoso de $5 \mathrm{~g} \mathrm{~L}^{-1}, \mathrm{~T} 3$ - extrato aquoso $10 \mathrm{~g} \mathrm{~L}^{-1}$, $\mathrm{T} 3$ - extrato aquoso de $15 \mathrm{~g} \mathrm{~L}^{-1} \mathrm{e} \mathrm{T} 4$ - extrato aquoso de $25 \mathrm{~g} \mathrm{~L}^{-1}$, sendo aplicados diretamente sobre as sementes três vezes por semana, no mesmo horário do dia. Para tanto, utilizou-se 6 $\mathrm{mL}$ de água destilada no controle e $6 \mathrm{~mL}$ de extrato aquoso nos tratamentos por placa durante as aplicações da primeira semana e, $5 \mathrm{~mL}$ a partir da segunda semana de experimento. A redução do volume das aplicações foi feita com o intuito de evitar que as placas ficassem com quantidade excessiva de líquido. As contagens das sementes germinadas foram realizadas durante 11 dias.

Foram calculadas as médias de germinação de sementes de E. plana para cada tratamento, além do Índice de Velocidade de Germinação (IVG). Através do cálculo descrito por Marguine (1962):

$$
\mathrm{IVG}=\mathrm{G} 1 / \mathrm{T} 1+\mathrm{G} 2 / \mathrm{T} 2+\ldots+\mathrm{Gn} / \mathrm{Tn}
$$

Onde: $\mathrm{G}=$ número de sementes germinadas naquele dia; $\mathrm{T}=$ tempo (dias)

Os dados foram submetidos a análise de variância (ANOVA) e regressão. A estatística foi realizada utilizando o software Action integrado ao Excel (Equipe Estatcamp, 2014).

\subsection{Análise cromatográfica dos extratos aquosos de Achyrocline satureioides}

O método utilizado para a análise dos componentes presentes nos extratos aquosos de A. satureioides foi separação de substâncias por meio da Cromatografia Líquida de Alta Eficiência (CLAE-DAD). Todos os produtos químicos foram de grau analítico. Os componentes metanol, ácido acético, ácido gálico, ácido clorogênico, ácido cafeico e ácido elágico foram adquiridos a Merck (Darmstadt, Alemanha). A quercetina, quercitrina, rutina, luteolina, kaempferol, catequina e epicatequina foram adquiridos da Sigma Chemical Co. (St. Louis, MO, EUA). A CLAE-DAD foi realizada com um auto injetor Shimadzu (SIL-20A) do sistema de CLAE (Shimadzu, Kyoto, Japão), equipado com bombas alternativas Shimadzu (LC-20AT) ligadas a um desgaseificador DGU 20A5 com integrador (CBM 20A) por arranjo de diodos (SPD-M20A) e software LC solution SP1 1,22. As análises foram realizadas em fase reversa sobre condições de gradiente utilizando coluna $\mathrm{C}_{18}(4,6 \mathrm{~mm}$ x $250 \mathrm{~mm})$ com partículas de $5 \mu \mathrm{m}$ de diâmetro. A fase móvel tinha composição formada por água, ácido acético a $2 \%$ (A) e metanol (B), sendo o gradiente de composição de: $5 \%$ de $\mathrm{B}$ durante 2 minutos, $25 \%$ de B até 10 minutos; 40, 50, 60, 70 e $80 \%$ de $\mathrm{B}$ a cada 10 minutos, método descrito por Barbosa Filho et al. (2014), com algumas modificações.

Os extratos e fase móvel foram filtrados através de um filtro de membrana de $0,45 \mu \mathrm{m}$ (Millipore), e em seguida desgaseificada por banho de ultrassons, antes da utilização, amostras de $A$. satureioides foram analisadas nas concentrações $25,15,10,5 \mathrm{mg} \mathrm{mL} \mathrm{m}^{-1}$. As soluções de normalização foram preparadas na fase móvel de CLAE em concentrações de 
0,030-0,250 $\mathrm{mg} \mathrm{mL}^{-1}$ para catequina, epicatequina, quercetina, quercitrina, luteolina, canferol e rutina e $0,045-0,500 \mathrm{mg} \mathrm{mL}^{-1}$ para o ácido gálico, ácido clorogênico, ácido elágico e ácido caféico.

Os picos cromatográficos foram confirmados por comparação do tempo de retenção e espectros de DAD (200-600 nm) com padrões de referência. Curvas de calibração para o ácido gálico: $\mathrm{Y}=1278,2+12674 \mathrm{x}(\mathrm{r}=0,9999)$; para o ácido clorogênico: $\mathrm{Y}=1195,2+13519 \mathrm{x}\left(\mathrm{R}^{2}=\right.$ 0,9997); para o ácido cafeico: $\mathrm{Y}=1198,1+$ 13348x $\left(\mathrm{R}^{2}=0,9997\right)$; para o ácido elágico: $\mathrm{Y}=$ $1265,6+11973 \mathrm{x} \quad\left(\mathrm{R}^{2}=0,9998\right) ;$ para $\mathrm{a}$ catequina: $\mathrm{Y}=1270,3+12671 \mathrm{x} \quad\left(\mathrm{R}^{2}=0,9999\right)$; para a epicatequina: $\mathrm{Y}=1185,7+12565 \mathrm{x}\left(\mathrm{R}^{2}=\right.$ 0,9998); para a rutina: $\mathrm{Y}=1249.8+13854 \mathrm{x}\left(\mathrm{R}^{2}\right.$ $=0,9997)$; para a quercetina: $\mathrm{Y}=1196,5+$ 13074x $\left(\mathrm{R}^{2}=0,9999\right)$; para a quercitrina: $\mathrm{Y}=$ $1175,3+12573 x\left(R^{2}=0,9998\right)$, para a luteolina: $\mathrm{Y}=1251,0+11983 \mathrm{x}\left(\mathrm{R}^{2}=0,9997\right)$ e para o campferol: $\mathrm{Y}=1194,8+13492 \mathrm{x}\left(\mathrm{R}^{2}=0,9999\right)$. As operações de cromatografia foram realizadas, todas, em temperatura ambiente.

Para os resultados do CLAE foi realizada análise estatística pelo teste Scott-Knott ( $\mathrm{p} \leq$ 0,05), utilizando o software Assistat versão 7.7.

\section{Resultados}

\subsection{Extratos de Achyrocline satureioides (Lam.) DC sobre a germinação de sementes de Eragrostis plana Nees}

A partir da análise de regressão observa-se que há um decréscimo na germinação das sementes de E. plana com a aplicação de extratos de de $A$. satureioides. $\mathrm{O}$ aumento unitário na concentração reduziu em $1,6 \%$ a germinação das sementes, passando de $72,8 \%$ para 33, 7\% sob as concentrações de 0 e $25 \mathrm{~g} \mathrm{~L}^{-}$ ${ }^{1}$, respectivamente. Nesse sentido, quanto maior a concentração do extrato de A. satureioides menor será a porcentagem de germinação de $E$. plana.

Os resultados para o IVG de sementes de $E$. plana quando submetidos a concentrações de extratos de A. satureioides são mostrados na Figura 2. Nota-se que quanto maior a concentração do extrato utilizado, menor os valores obtidos para o IVG. Estima-se que para cada aumento unitário na concentração dos extratos aquosos de A. satureioides ocorreu redução de 0,7 no IVG, ou seja, $3 \%$ obtendo-se médias 24,9 na testemunha e 7,2 sob a concentração de $25 \mathrm{~g} \mathrm{~L}^{-1}$. Como foi observado para a porcentagem de germinação o IVG de $E$. plana também diminui com o aumento da concentração nos extratos de A. satureioides.

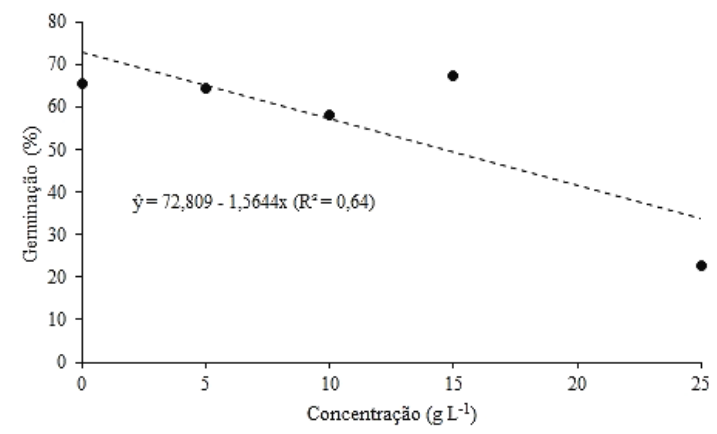

Figura 1 Germinação de sementes de Eragrostis plana Nees sob o efeito das concentrações de extratos aquosos de Achyrocline satureioides (Lam.) DC.

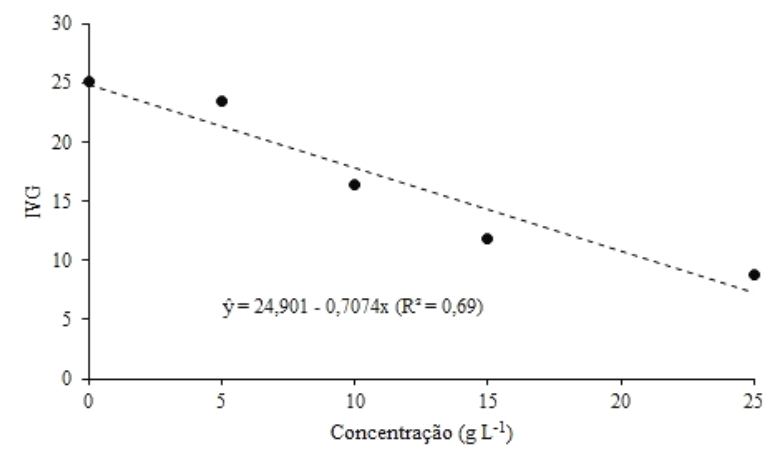

Figura 2 Índice de velocidade de germinação de sementes de Eragrostis plana Nees sob o efeito das concentrações de extratos aquosos de Achyroclines satureioides (Lam.) DC.

\subsection{Análise cromatográfica dos extratos aquosos de Achyrocline satureioides (Lam.) DC}

As médias obtidas, por meio da análise de CLAE, dos extratos aquosos de flores de $A$. satureioides estão na Tabela 1 e a representação do perfil cromatográfico na Figura 3. O CLAE revelou a presença do ácido gálico $\left(t_{R} 12,09 \mathrm{~min}\right.$, pico 1$)$, catequina $\left(t_{R}=17,34 \mathrm{~min}\right.$, pico 2$)$, ácido clorogenico $\left(t_{R}=23,68 \mathrm{~min}\right.$, pico 3$)$, ácido caféico $\left(t_{R}=25,01 \mathrm{~min}\right.$, pico 4$)$, epicatequina $\left(t_{R}\right.$ $=31,98 \mathrm{~min}$, pico 5), ácido elágico $\left(\mathrm{t}_{\mathrm{R}}=34,92\right.$ min, pico 6), rutina $\left(t_{R}=40,12 \mathrm{~min}\right.$, pico 7), quercitrina $\left(t_{R}=44,71 \mathrm{~min}\right.$, pico 8$)$, quercetina $\left(t_{R}=49,83\right.$ min, pico 9), campferol $\left(t_{R}=54,69\right.$ 
Extratos de Achyrocline satureioides (Lam.) DC. sobre a germinação "in vitro" de ...

Freitas et al.

min, pico 10) e luteolina $\left(t_{R}=56,03\right.$ min, pico $11)$.

A concentração de $5 \mathrm{~g} \mathrm{~L}^{-1}$ não apresentou compostos com concentrações significativamente maiores. No entanto, nas demais concentrações o composto em maior concentração foi a quercitrina, seguida pelo ácido cafeico e pela rutina, com os demais compostos em concentrações inferiores a $10 \mathrm{mg}$ $\mathrm{g}^{-1}$ (Tabela 1 e Figura 3).

Tabela 1 Comparação entre compostos $\left(\mathrm{mg} \mathrm{g}^{-1}\right)$ encontrados nas diferentes concentrações dos extratos aquosos de Achyrocline satureioides (Lam.) DC.

\begin{tabular}{lcccc}
\hline \multicolumn{1}{c}{ Compostos } & $5 \mathrm{~g} \mathrm{~L}^{-1}$ & $10 \mathrm{~g} \mathrm{~L}^{-1}$ & $15 \mathrm{~g} \mathrm{~L}^{-1}$ & $25 \mathrm{~g} \mathrm{~L}^{-1}$ \\
\hline Ácido gálico & $1.93 \mathrm{a}$ & $2.06 \mathrm{f}$ & $3.17 \mathrm{~h}$ & $5.78 \mathrm{f}$ \\
Catequina & $0.52 \mathrm{a}$ & $0.81 \mathrm{~g}$ & $1.25 \mathrm{k}$ & $1,92 \mathrm{i}$ \\
Ácido clorogênico & $1.05 \mathrm{a}$ & $1.82 \mathrm{f}$ & $1.71 \mathrm{j}$ & $2.86 \mathrm{~h}$ \\
Ácido caféico & $6.94 \mathrm{a}$ & $9.72 \mathrm{~b}$ & $13.10 \mathrm{~b}$ & $21.23 \mathrm{~b}$ \\
Ácido elágico & $0.73 \mathrm{a}$ & $1.08 \mathrm{~g}$ & $1.76 \mathrm{i}$ & $2.80 \mathrm{~h}$ \\
Epicatequina & $2.12 \mathrm{a}$ & $3.38 \mathrm{~d}$ & $5.17 \mathrm{e}$ & $8.62 \mathrm{~d}$ \\
Rutina & $5.72 \mathrm{a}$ & $8.78 \mathrm{c}$ & $12.83 \mathrm{c}$ & $15.10 \mathrm{c}$ \\
Quercitrina & $8.14 \mathrm{a}$ & $10.70 \mathrm{a}$ & $14.67 \mathrm{a}$ & $24.10 \mathrm{a}$ \\
Quercetina & $2.20 \mathrm{a}$ & $3.35 \mathrm{~d}$ & $5.27 \mathrm{~d}$ & $8.72 \mathrm{~d}$ \\
Isoquercitrina & $0.69 \mathrm{a}$ & $0.91 \mathrm{~g}$ & $3.22 \mathrm{~g}$ & $5.42 \mathrm{~g}$ \\
Kaempferol & $2.00 \mathrm{a}$ & $2.56 \mathrm{e}$ & $4.61 \mathrm{f}$ & $7.94 \mathrm{e}$ \\
\hline
\end{tabular}

*Médias seguidas pela mesma letra minúscula na coluna não diferem significativamente entre si pelo teste Scott-Knott ( $\mathrm{p} \leq 0,05$ ).
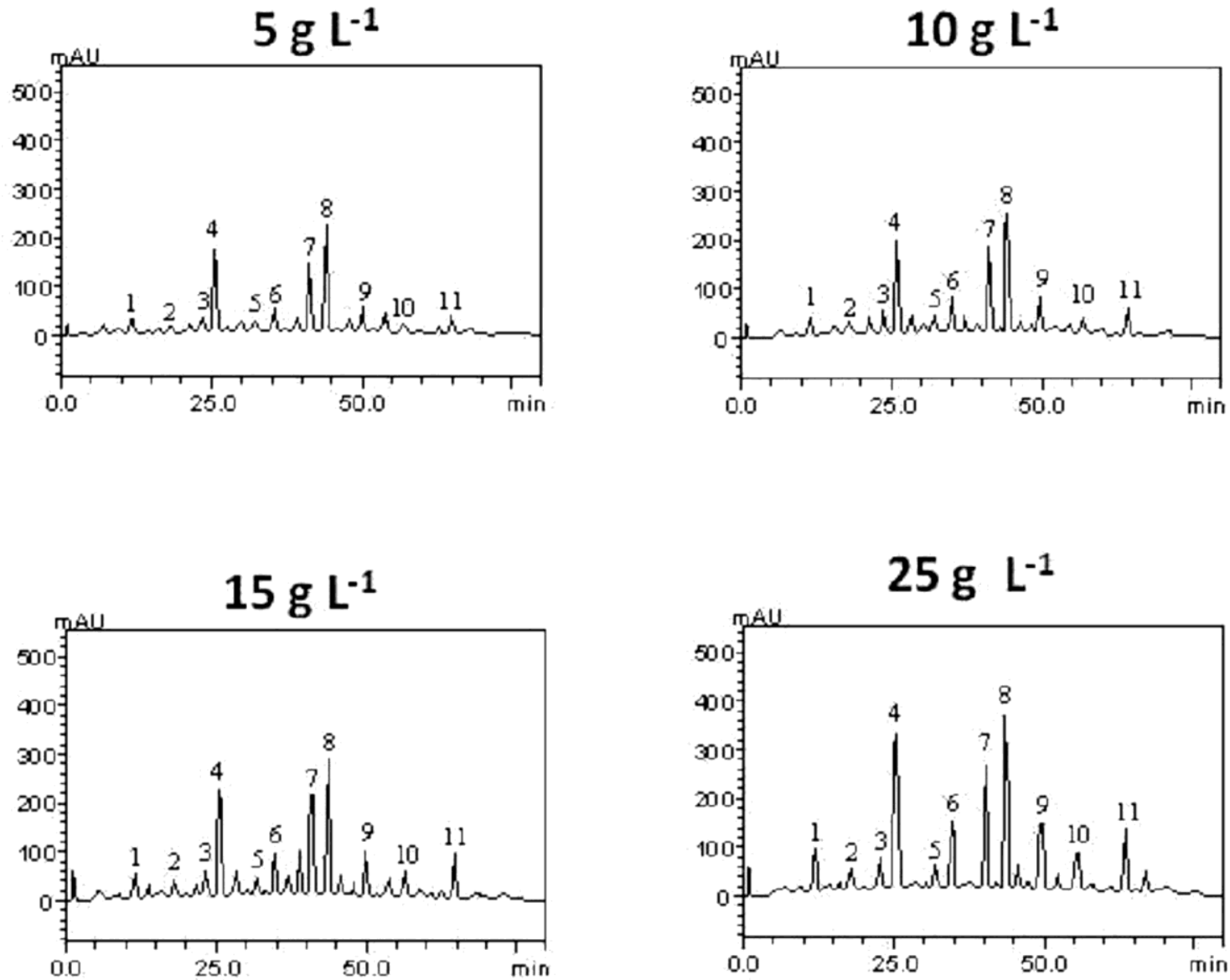

Figura 3 Representação do perfil de cromatografia líquida de alta eficiência das infusões de flores de Achyrocline satureioides. Ácido gálico (pico 1), catequina (pico 2), ácido clorogênico (pico 3), ácido caféico (pico 4), epicatequina (pico 5), ácido elágico (pico 6), rutina (pico 7), quercitrina (pico 8), quercetina (pico 9), campferol (pico 10) e luteolina (pico 11). 


\section{Discussão}

\subsection{Extratos de Achyrocline satureioides (Lam.) DC sobre a germinação de sementes de Eragrostis plana Nees}

A partir dos resultados obtidos pode-se observar que com o aumento da concentração dos extratos aquosos de A. satureioides ocorreu efeito antiproliferativo sobre sementes de $E$. plana, reduzindo a germinação e o índice de velocidade de germinação.

Ao analisar a atividade alelopática de substâncias químicas produzidas por Myrcia guianensis (Aubletet) A. P. de Candolle sobre sementes de Mimosa pudica L. e Senna obtusifolia (L.) H.S. Irwin \& Barney, Souza Filho et al. (2006), relataram que houve atividade inibitória, além de estimulação da germinação de sementes. A maior parte da inibição foi observada para a espécie $M$. pudica e, o efeito reverso, para a espécie $S$. obtusifolia. Nesse caso, a redução da germinação estava associada aos fatores concentração e planta receptora.

Em trabalho realizado por Souza et al. (2005), foi testado o efeito fitotóxico da $A$. satureioides sobre a germinação de Lactuca sativa observou-se que para primeira contagem de germinação os valores aumentaram até a concentração de $10 \mathrm{mg} \mathrm{mL}^{-1}$. Mas, com do aumento da concentração do extrato para $20 \mathrm{mg}$ $\mathrm{mL}^{-1}$, verificou-se a redução da germinação. Os autores ainda relataram que com o aumento da concentração dos extratos de Bauhinia candicans Benth. e de Luehea divaricata Mart. houve diminuição da percentagem de germinação em sementes de $L$. sativa.

Também foi analisado o efeito de extratos de folhas secas e frescas de Persea americana Mill sobre sementes de L. sativa. Os autores constataram que a porcentagem de germinação foi alterada ao decorrer do aumento da concentração dos extratos. Ainda, ocorreu redução no IVG com diminuição no número médio de sementes de alface germinadas em relação ao aumento das concentrações de extratos de P. americana (Borella et al., 2009). Quando analisado os extratos de folhas secas de Ricinus communis L. sobre a germinação de sementes de $L$. sativa, os extratos apresentaram efeito citotóxico nas diferentes concentrações testadas. Sendo que na mais alta concentração,
(20 mg mL $\mathrm{m}^{-1}$ ), ocorreu oxidação e impedimento do crescimento das radículas (Cuchiara, 2007).

Quanto aos dados analisados, constata-se que o aumento na concentração dos extratos de $A$. satureioides reduziram o IVG das sementes de E. plana. $\mathrm{O}$ mesmo ocorreu quando foi avaliado o efeito dos extratos de Baccharis trimera (Less.) DC. sobre a germinação de sementes de E. plana., ocorrendo uma queda na taxa de germinação com o aumento da concentração dos extratos. Nas concentrações mais elevadas, $75 \mathrm{~g}$ $\mathrm{L}^{-1}$ e $100 \mathrm{~g} \mathrm{~L} \mathrm{~L}^{-1}$, houve inibição total da germinação (Gonçalves, 2014).

Resultado semelhante foi apresentado por Borella e Pastorini (2009), quando analisou-se a influência de extratos das folhas de Phytolacca dioica L. sobre a porcentagem e velocidade de germinação de sementes de Solanum lycopersicum L. e B. pilosa. Neste trabalho demonstrou-se que nas maiores concentrações dos extratos de $P$. dioica, ocorreu redução na germinação das duas espécies estudadas, sendo que na maior concentração, $8 \%(\mathrm{~m} / \mathrm{v})$, a germinação foi totalmente inibida.

Ao analisarem a germinação de sementes de L. sativa e Lycopersicum esculentum Mill. submetidas a extratos de folhas frescas, secas e frutos de Duranta repens L., Tur et al., 2010, notaram que todos os extratos influenciaram significativamente na porcentagem germinação de sementes de L. esculentum. Também foi relatado que com o aumento das concentrações dos extratos de $D$. repens, a velocidade de germinação de $L$. sativa foi alterada, ocorrendo o atraso na germinação. Para L. esculentum apenas extratos de folhas frescas e secas influenciaram na velocidade de germinação das sementes, onde as maiores concentrações demonstraram inibição da germinação.

\subsection{Análise cromatográfica dos extratos aquosos de Achyrocline satureioides (Lam.) DC}

Os resultados obtidos para análise dos compostos dos extratos de marcela por CLAEDAD demonstraram a presença de quercitrina, ácido caféico e rutina em maiores teores. Em trabalho de Broussalis et al. (1989) observou-se a presença de ácido caféico, clorogênico e ácido isoclorogênico na planta A. satureioides, principalmente nas partes aéreas. Em pesquisa realizada por Gugliucci et al. (2002), também 
ocorreu a presença de ácidos fenólicos, como ácido cafeico e ácido clorogenico, e também de flavonoides como, luteolina e quercetina na composição de extratos de A. satureioides.

Compostos como o ácido clorogênico e o ácido caféico, dentre outros, têm sido estudados e descritos como inibidores de germinação de sementes. Ao avaliar a ação alelopática dos compostos presentes em extratos de Calopogonium mucunoides Desv. sobre a germinação de sementes de Cassia tora L., Mimosa pudica L. e Cassia occidentalis hort. ex Steud., Santos et al. (2011) demonstraram que o ácido clorogênico, o ácido caféico, quercetina, rutina $\mathrm{e}$ o caempferol inibiram significativamente a germinação das sementes. Sendo as espécies $M$. pudica e $C$. tora foram as que tiveram a germinação mais reduzida.

Quando analisado o efeito fitotóxico de compostos presentes em folhas de Eugenia flavescens DC sobre sementes de Mimosa pudica e Senna obtusifolia, houve relato de que a mistura dos flavonoides, quercitrina e catequina, apresentou efeito fitotóxico e inibição da germinação das sementes testadas. O efeito inibitório foi maior para as sementes de $M$. pudica, com uma porcentagem de redução de germinação de $92,1 \%$ na concentração de 150 ppm (Cantanhede Filho et al., 2017).

Trabalhos como de Vargas et al. (1990), demonstraram que extratos de A. satureioides apresentam atividade genotóxica em microorganismos, essa atividade foi relacionada com a presença de ácido cafeico e quercetina nos extratos. Teixeira et al. (2003) realizaram estudo que atribui aos compostos taninos, encontrados em extratos de A. satureioides, inibição da divisão celular em $A$. cepa e inibição da germinação, revelando que extratos aquosos de A. satureioides tem grande poder inibitório sobre outras plantas. O mesmo é colocado pelo autor, Arisawa (1994), que evidenciou a atividade antiproliferativa de extratos de marcela em estudos realizados "in vitro".

A redução na germinação e no IVG de $E$. plana ocorreu no presente estudo e deve estar relacionada com os compostos fenólicos e flavonoides presentes nos extratos de $A$. satureioides, e por estarem em concentrações superiores, a quercitrina, o ácido cafeico e a rutina podem ser os principais responsáveis por essa atividade de inibição da germinação e IVG. Ainda, pode-se acrescentar que o sinergismo ou o antagonismo entre os compostos presentes nos extratos podem ter relação com os efeitos observados no presente estudo (Probst, 2012).

\section{Conclusão}

Os extratos de Achyrocline satureioides reduzem a porcentagem de germinação de Eragrostis plana. A concentração de $25 \mathrm{~g} \mathrm{~L}^{-1}$ do extrato de A. satureioides é a mais eficaz, na redução da porcentagem de germinação, apresentando o maior efeito antiproliferativo;

Os compostos encontrados nos extratos de flores de A. satureioides são quercitrina, rutina e ácido caféico, os quais podem ter relação com os efeitos antiproliferativos observados neste trabalho.

\section{Agradecimentos}

Os autores agradecem à EMBRAPA Pecuária Sul de Bagé e à Coordenação de Aperfeiçoamento de Pessoal de Nível Superior (CAPES). Além disso, agradecemos a Prof ${ }^{a}$. Dra. Margareth Linde Athayde (in memorian) pela colaboração neste trabalho.

\section{Referências}

Almeida, K.; Câmara, F. L. A. Preparados homeopáticos e adubação verde no controle de Cyperus rotundus L. Revista Ceres, v.59, n.3, p.422-426, 2012. http://dx.doi.org/10.1590/S0034$\underline{737 X 2012000300019}$

Arisawa, M. Cell growth inhibition of KB cells by plant extracts. Nature Medicine, v.48, n.4, p.338-347, 1994. http://dl.ndl.go.jp/view/download/digidepo_10758800_po ART0009808205.pdf?content $\mathrm{No}=1$ \&alternative $\mathrm{No}=$

Barbosa Filho, V. M.; Waczuk, E. P.; Kamdem, J. P.; Abolaji, A. O.; Lacerda, S. R.; Costa, J. G. M.; Menezes, I. R. A.; Boligon, A. A.; Athayde, M. L.; Rocha, J. B. T.; Posser, T. Phytochemical constituents, antioxidant activity, cytotoxicity and osmotic fragility effects of Caju (Anacardium microcarpum). Industrial Crops and Products, v.55, p. 280288 , 2014. https://doi.org/10.1016/j.indcrop.2014.02.021

Borella, J.; Pastorini, L. H. Influência alelopática de Phytolacca dioica L. na germinação e 
crescimento inicial de tomate e picão-preto. Biotemas, v.22, n.3, p.67-75, 2009. https://doi.org/10.5007/2175-7925.2009v22n3p67

Borella, J.; Wandscheer, A. C. D.; Bonatti, L. C.; Pastorini, L. H. Efeito alelopático de extratos aquosos de Persea americana Mill. sobre Lactuca sativa L. Revista Brasileira de Biociências, v.7, n.3, p.260-265, 2009. http://www.ufrgs.br/seerbio/ojs/index.php/rbb/article/vie $\underline{\mathrm{w} / 1236}$

Brass, F. E. B. Análise da atividade alelopática de extrato aquoso de falsa-murta sobre a germinação de picão-preto e caruru. Enciclopédia Biosfera, v.5, n.8, p.1-19, 2009. http://www.conhecer.org.br/enciclop/2009B/ANALISE\% 20DE\%20ATIVIDADE\%20ALELOPATICA.pdf

Broussalis, A. M.; Ferraro, G. E.; Gurni, A. A.; Coussio, J. D. Aspectos fitoquímicos de especies argentinas del gênero Achyrocline. Acta Farmaceutica Bonaerense, v.8, n.1, p.11-16, 1989. http://hdl.handle.net/10915/7251

Cantanhede Filho, A. J.; Santos, L. S.; Guilhon, G. M. S. P.; Zoghbi, M. G. B.; Ports, P. S.; Rodrigues, I. C. S. Triterpenoides, fenólicos e efeito fitotóxico das folhas de Eugenia flavescens DC (Myrtaceae). Química Nova, v.40, n.3, p.252-259, 2017. http://dx.doi.org./10.21577/0100-4042.20160190

Cuchiara, C. C.; Borges, C. S.; Sopezki, M. S.; Souza, S. A. M.; Bobrowski, V. L. Efeito Antiproliferativo dos Extratos Aquosos de Mamona (Ricinus communis L.). Revista Brasileira de Biociências, v.5, n.S2, p.639641, 2007. http://www.ufrgs.br/seerbio/ojs/index.php/rbb/article/vie $\underline{w} / 557$

Equipe Estatcamp. Software Action. São Carlos: $\quad$ Estatcamp, 2014. http://www.portalaction.com.br

Fachinetto, J. M.; Bagatini, M. D.; Durigon, J.; Silva, A. C. F.; Tedesco, S. B. Efeito antiproliferativo das infusões de Achyrocline satureioides sobre o ciclo celular de Allium сера. Revista Brasileira de Farmacognosia, v.17, n.1, p.49-54, 2007. http://dx.doi.org/10.1590/S0102-695X2007000100011

Ferreira, N. R.; Medeiros, R. B.; Soares, G. L. G. Potencial alelopático do capim-annoni-2 (Eragrostis plana Nees) na germinação de sementes de gramíneas perenes estivais.
Revista Brasileira de Sementes, v.30, n.2, p.43-50, 2008. http://dx.doi.org/10.1590/S010131222008000200006

Fiorenza, M.; Dotto, D. B.; Boligon, A. A.; Boligon, A. A.; Athayde, M. L.; Vestena, S. Análise fitoquímica e atividade alelopática de extratos de Eragrostis plana Nees (capimannoni). Iheringia, série Botânica, v.71, n.2, p.193-200,

2016. https://isb.emnuvens.com.br/iheringia/article/viewFile/53 $\underline{6 / 300}$

Focht, T. Ecologia e dinâmica do capimannoni-2 (Eragrotis plana Nees), uma invasora dos campos sulinos: prevenção da sua expansão. 2008. 132 f. Tese (Doutorado em Ecologia) - Instituto de Biociências, Universidade Federal do Rio Grande do Sul, Porto Alegre, 2008.

Gonçalves, C. E. P. Alelopatia de carqueja (Baccharis trimera) e ação de fungos em capim-annoni (Eragrostis plana Ness). 2014. 88 f. Dissertação (Mestrado em Agrobiologia) - Universidade Federal de Santa Maria, Santa Maria, 2014.

Gugliucci, A.; Menini, T. Three different pathways for human LDL oxidation are inhibited in vitro by water extracts of the medicinal herb Achyrocline satureioides. Life Sciences, v.71, n.6, p.693-705, 2002. http://dx.doi.org/10.1016/S0024-3205(02)01734-4

Holzschuh, M. H. Estudo da estabilidade de produtos secos obtidos a partir de Achyrocline satureioides (Lam.) DC. 2008. 196f. Asteracea. Tese (Doutorado em Ciências Farmacêuticas) - Faculdade de Farmácia, Universidade Federal do Rio Grande do Sul, Porto Alegre, 2008.

Kremer, T. C. B.; Yamashita, O. M.; Felito, R. A.; Ferreira, A. C. T.; Araújo, C. F. Atividade alelopática de extrato aquoso de Croton glandulosus L. na germinação e no desenvolvimento inicial de alface. Revista da Universidade do Vale do Rio Verde, v.14, n.1, p.890-898, 2016. http://dx.doi.org/10.5892/ruvrd.v14i1.2628

Lisboa, C. A. V.; Medeiros, R. B.; Azevedo, E. B.; Patino, H. O.; Carlotto, S. B.; Garcia, R. P. A. Poder germinativo de sementes de capimannoni-2 (Eragrostis plana Nees) recuperadas em fezes de bovinos. Revista Brasileira de 
Zootecnia, v.38, n.3, p.405-410, 2009. http://dx.doi.org/10.1590/S1516-35982009000300001

Marguine, J. D. Speed of germination aid in selection and evaluation for seedling emergence and vigor. Crop Science, v.2, n.2, p.176-177, 1962. https://eurekamag.com/pdf/014/014195562.pdf

Mota, F. M.; Carvalho, H. H. C.; Wiest, J. M. Atividade antibacteriana in vitro de inflorescências de Achyrocline satureioides (Lam.) DC. -Asteraceae ("macela", "marcela") sobre agentes bacterianos de interesse em alimentos. Revista Brasileira de Plantas Medicinais, v.13, n.3, p.298-304, 2011. http://dx.doi.org/10.1590/S1516-05722011000300008

Oliveira, M. G. F.; Sousa, F. D. A.; Oliveira, K. R. M.; Alvino, F. C. G.; Góis, D. S.; Lopes, K. P. Potencial alelopático de extratos aquosos de folhas de Mimosa tenuiflora e semente de Achyrocline satureioides sobre a germinação e desenvolvimento de plântulas de alface. Revista Agropecuária Científica no Semiárido, v.10, n.3, p.26-33, 2014. http://revistas.ufcg.edu.br/acsa/index.php/ACSA/article/vi ewFile/469/pdf

Pereira, J. C.; Paulino, C. L. A.; Granja, B. S.; Santana, A. E. G.; Endres, L.; Souza, R. C. Potencial alelopático e identificação dos metabólitos secundários em extratos de Canavalia ensiformis L. Revista Ceres, v.65, n.3, p.243-252, 2018. http://dx.doi.org/10.1590/0034-737x201865030004

Pillar, V. P.; Müller, S. C.; Castilhos, Z. M. S.; Jacques, A. V. A. Campos Sulinos, conservação e uso sustentável da biodiversidade. $1^{\text {a }}$ Ed. Brasília: MMA, 2009. 403p.

Probst, I. S. Atividade antibacteriana de óleos essenciais e avaliação de potencial sinérgico. 2012. 112 f. Dissertação (Mestrado em Biologia Geral e Aplicada) - Instituto de Biociências de Botucatu, Universidade Estadual Paulista, São Paulo, 2012.

Queiroz, R. L.; Pires, V.; Bartelega, A.; Carvalho, J. W. M.; Serafim, A. Avaliação de extrato de Melaleuca alternifolia (Cheel) na germinação de Brachiaria brizantha. Revista Fitos, v.10, n.4, p.397-403, 2016. http://dx.doi.org/10.5935/2446-4775.20160028

Reis, J. C. L.; Oliveira, O. L. P. Considerações sobre capim annoni 2 (Eragrostis plana
Nees). Bagé: Embrapa Pecuária Sul, 1978. 16 p. (Circular técnica, 2). https://ainfo.cnptia.embrapa.br/digital/bitstream/item/678 57/1/CR-2-1978.pdf

Santos, S.; Moraes, M. L. L.; Rezende, M. O. O.; Souza Filho, A. P. S. Potencial alelopático e identificação de compostos secundários em extratos de calopogônio (Calopogonium mucunoides) utilizando eletroforese capilar. Eclética Química, v.36, n.2, p.51-68, 2011. http://dx.doi.org/10.1590/S0100-46702011000200003

Souza, S. A. M.; Cattelan, L. V.; Vargas, D. P.; Piana, C. F. B.; Bobrowski, V. L.; Rocha, B. H. G. Efeito de extratos aquosos de plantas medicinais nativas do Rio Grande do Sul sobre a germinação de sementes de alface. Publicatio UEPG: Ciências Biológicas e da Saúde, v.11, n.3, p.29-38, 2005. http://dx.doi.org/10.5212/publicatio\%20uepg.v11i3.418

Souza Filho, A. P. S.; Santos, R. A.; Santos, L. S.; Guilhon, G. M. P.; Santos, A. S.; Arruda, M. S. P.; Muller, A. H.; Arruda, A. C. Potencial alelopático de Myrcia guianensis. Planta daninha, v.24, n.4, p.649-656, 2006. http://dx.doi.org/10.1590/S0100-83582006000400005

Souza-Moreira, T. M.; Salgado, H. R. N., Pietro, R. C. L. R. O Brasil no contexto de controle de qualidade de plantas medicinais. Revista Brasileira de Farmacognosia, v.20, n.3, p.435-440, 2010. http://dx.doi.org/10.1590/S0102$\underline{695 \times 2010000300023}$

Teixeira, R. O.; Camparoto, M. L.; Mantovani, M. S.; Vicentini, V. E. P. Assessment of two medicinal plants, Psidium guajava $\mathrm{L}$. and Achillea millefolium L., in vitro and in vivo assays. Genetic and Molecular Biology, v.26, n.4, p.551-555, 2003. http://dx.doi.org/10.1590/S1415-47572003000400021

Tonhi, E.; Kenneth, E. C.; Jardim, I. C. S. F.; Collins, C. H. Fases estacionárias para cromatografia de alta eficiência em fase reversa (CLAE-FR) baseadas em superfícies de óxidos inorgânicos funcionalizados. Química Nova, v.25, n.4, p.616-623, 2002. http://dx.doi.org/10.1590/S0100-40422002000400017

Tur, C. M.; Borella, J.; Pastorini, L. H. Alelopatia de extratos aquosos de Duranta repens sobre a germinação e crescimento inicial de Lactuca sativa e Lycopersicum esculentum. Revista Biotemas, v.23, n.2, p.13$22,2010$. 
Extratos de Achyrocline satureioides (Lam.) DC. sobre a germinação "in vitro" de ... Freitas et al.

https://periodicos.ufsc.br/index.php/biotemas/article/viewFi le/21757925.2010v23n2p13/15100

Vargas, V. M.; Motta, V. E. P.; Leitão, A. C.; Henriques, J. A. P. Mutagenic and genotoxic effects of Achyrocline satureoides in prokaryotic organisms. Mutation Research, v.240, n.1, p.13-18, 1990. https://doi.org/10.1016/0165-1218(90)90003-K 